\title{
Trabalho do professor pesquisador diante da expansão da pós-graduação no Brasil pós-LDB
}

\author{
JOÃO DOS REIS SILVA JÚNIOR \\ Universidade Federal de São Carlos \\ LUCIANA RODRIGUES FERREIRA \\ Universidade Federal de São Carlos \\ FABÍOLA BOUTH GRELLO KATO \\ Universidade Federal de São Carlos
}

Não se trata de afirmar que publicar artigos seja algo em si mesmo ruim. Trata-se, isto sim, de se atentar para o fato de que o modelo produtivista está impondo um determinado ritmo para o fazer cientifico e exigindo que os temas de pesquisa sejam adequados a esse ritmo. E, num círculo vicioso, a comunidade acadêmica está se habituando a consumir preferencialmente trabalhos de leitura mais rápida e que se enquadrem nos temas da moda. Nesse contexto, não há meio termo: ou questionamos o modelo de sociedade inerente ao modelo produtivista do fazer cientifico ou acabaremos por considerar como natural e inevitável o empobrecimento do trabalho acadêmico.

Duarte, 2002, p. 6

Nas duas últimas décadas o Brasil passou por mudanças estruturais em razão de sua particularidade histórica e das mudanças estruturais da economia em âmbito planetário. A partir do trânsito da década de 1980 para a de 1990, o país, mais uma vez, adaptou-se às mudanças mundializadas no plano econômico, aderindo ao que François Chesnais (1996) vem chamando de regime de predominância financeira. Esta adesão impôs ao Brasil, à sua maneira, alterar os fundamentos de sua economia e passar a fazer parte de forma definitiva e sem volta da economia mundial. Este é um marco para o entendimento de muitas mudanças que vem se operando 
nacionalmente. Contudo, talvez, o mais relevante seja o movimento de mudança nas instituições republicanas brasileiras.

Este movimento tem sua origem na reforma do aparelho de Estado iniciada em 1995 e que, com continuidades e rupturas, tornou-se um sólido processo com diferenças entre governos distintos em razão das alianças e práticas políticas dos partidos que se põem na condição da base aliada governamental.

A contribuição deste breve texto consiste em analisar as mudanças pelas quais passou a instituição republicana universitária e as mudanças do trabalho do professor desta. Especificamente, interessa-nos discutir aqui, de modo particular, sobre as mudanças ocorridas na universidade pública, com interesse específico nas suas relações entre a expansão ocorrida na pós-graduação e as consequências para o trabalho docente, enfatizando o nível da pós-graduação, locus privilegiado da produção da Ciência, Tecnologia e Inovação (CT\&I), com profundas características de mercantilização do conhecimento produzido. Neste movimento, a universidade pública fora reposicionada, assumindo novas funções sociais e econômicas. As mudanças ocorridas teriam intensificado o trabalho do professor e acentuado o processo de precarização das relações de trabalho na instituição universitária.

\section{A MUNDIALIZAÇÃO DO CAPITAL, ACUMULAÇÃO FINANCEIRA E INSTITUIÇÕES REPUBLICANAS NO BRASIL}

O entendimento da radical mudança das instituições republicanas brasileiras é possível se compreendermos as transformações pelas quais passou a economia mundial e como este processo se configura no Brasil. Chesnais (idem), em seu livro A mundialização do capital, observa que a redução da relevância das fronteiras nacionais e a crescente presença das corporações mundiais sem um país que se situe como a matriz corporativa (footloose capital $)^{1}$ produziu uma centralização de capital em escala mundial. Considerando a importância dos conglomerados de grupos de capital, Chesnais (idem) caracteriza esta nova situação pela realocação industrial, um processo colocado e induzido pela redução e desregulação dos custos sobre o trabalho, pela intersecção da indústria, serviços e das finanças, pela rentabilidade da propriedade da riqueza e a predominância financeira sobre os demais ciclos de movimentação do capital.

$\mathrm{O}$ autor francês radicaliza seus argumentos ao assegurar que a mundialização está embasada no capital financeiro, especialmente na sua forma de moeda: o dólar estadunidense. Esta moeda é, para o autor, a pressuposição e o resultado do progresso de todas as economias mundiais. Fato que eventualmente pode ter levado David Harvey a escrever o brilhante livro O Novo Imperialismo e o recente The Enigma

1 Uma indústria cuja localização não é influenciada fortemente por acesso, quer a materiais ou mercados, e que pode, portanto, operar dentro de uma gama muito ampla de locais. Qualquer forma de negócio "linha direta", operado quase que totalmente através do telefone, o fac-símile e as novas tecnologias de comunicação e informação, seria um exemplo, também liberada das restrições de localização de capital livre. 
of Capital. Este novo quadro mundial da predominância financeira produz maior impacto em países não desenvolvidos, os que se encontram na "periferia" do sistema econômico mundial (Paulani; Oliveira, 2007).

Em época anterior à União Europeia, ainda guardava-se certo grau de autonomia em relação aos princípios referidos. Contudo, a crise europeia atual e a recente previsão da Organização das Nações Unidas (ONU) de que a economia mundial sofrerá uma retração mostram o quanto o Velho Continente e mesmo os Estados Unidos (EUA) sempre estiveram frágeis diante da predominância financeira. Atualmente, a maioria dos países europeus vê-se impelida a seguir à risca as diretrizes do Banco Mundial, do Fundo Monetário Internacional e do Banco Central Europeu (a "troica", como denominam os portugueses). Fato que parece desvelar a face institucional do capital financeiro e do poderio bélico americano (veja-se a nova política de defesa dos EUA).

No caso japonês, acontece algo semelhante a um paradoxo. Apesar do que se expôs, o Japão investe a maioria de seu superávit em Bônus do Tesouro Nacional dos EUA. Neste caso, financia a dívida interna norte-americana. No caso da China e da Índia, emergentes como o Brasil, é necessário indagar se estariam mudando a divisão mundial do trabalho. Os três oferecem capital no mercado mundial para suportar suas taxas de crescimento econômico. O dólar - dinheiro mundial - consiste no retorno das exportações de produtos chineses e dos serviços qualificados ou não da Índia. Não por acaso, recentemente, os chineses, em pronunciamento oficial, anunciaram que não pretendiam trocar o dólar americano como âncora de suas divisas externas. O dólar, apesar da crise econômica planetária, se fortalece na condição de dinheiro mundial ao lado do poderio bélico dos EUA. Este é o sentido da predominância financeira, como sugere Chesnais (1996).

Nas antigas periferias, tal como a América Latina - e o Brasil como um caso exemplar -, o processo toma forma primeiramente de um aumento da dívida interna e agora assume a posição de um país que se torna plataforma internacional de produção de valor para a valorização financeira. Neste contexto do sistema monetário internacional, todas as economias são parte de uma economia mundial e figuram como um subespaço do mundo, com exceção dos EUA. A diferença entre os gigantes asiáticos e a América Latina consiste no volume de comércio internacional, contudo, todos internalizaram o capital mundializado em Investimentos Estrangeiros Diretos (IED), ou joint ventures, que em momentos de crise tendem a investir em países em desenvolvimento.

Em 2010, quando a América Latina aumentou em mais de 40\% no fluxo de IED, o Brasil apresentou maior crescimento com 87\% a mais, em relação a 2009, especialmente pelas demandas nas áreas de recursos naturais, mineração metálica, hidrocarbonetos e alimentos (CEPAL, 2010, p. 8). Isso se confirma nas notícias cotidianas: a Folha de S. Paulo (Investimento estrangeiro..., 2011) anunciou que "nos 12 meses até setembro, esse tipo de entrada de capital chegou a impressionantes US $\$ 76,3$ bilhões" no país e acrescenta que tais investimentos permitiram ao "Brasil passar, de 2009 para 2010 , da $15^{\text {a }}$ para a 5a posição entre os principais destinos de IED no mundo". E isto contribui para que o quinhão do país no fluxo global de investimento estrangeiro direto chegue neste ano ao nível recorde de 5,4\%. 
Recentemente a Revista UOL, em notícia com a manchete "Montadoras enviam ao exterior US $\$ 5,58$ bi faturados no Brasil em 2011” (Kutney, 2012), mostrava de forma alardeante como o IED, tão aclamado aqui no país, sai pelos ralos. Assim, vai junto com ele o valor produzido pela força de trabalho brasileira, qualificada pelos programas de natureza profissional como o Programa Universidade para Todos (PROUNI), o Programa Nacional de Acesso ao Ensino Técnico e Emprego (PRONATEC), o Programa de Financiamento Estudantil (FIES), pelos mestrados profissionalizantes, pelo incentivo à formação profissionalizante dos graduandos por meio das bolsas de iniciação científica tecnológica e pela disposição do governo de assim continuar, como fica evidente na análise do Plano Nacional de Pós-Graduação (PNPG 2011/2020). Além das muitas pesquisas aplicadas à indústria automobilística produzidas nas universidades públicas do país, consolidando, ainda, uma cultura das famílias e do pequeno poupador, cujos valores guardados, outrora, permaneciam na poupança nacional, e, agora, se vão também ao mercado mundial de capitais. O Estado é o maior indutor e avalista de todo este processo.

Em acréscimo, vale dizer que tais programas educacionais dirigidos às escolas privadas e o financiamento das pesquisas a que se referiu são bancados pelo fundo público que, em contrapartida, também banca o ramo automobilístico brasileiro por meio de isenções de impostos e outras facilidades. Esta é a dimensão intangível e pouco vista do investimento externo (ou estrangeiro) direto (IED), que por aqui é visto como um medidor de como o país se tornou viável, isto é, uma excelente praça bursátil no mercado mundial de capitais.

A julgar pelos lucros que receberam, as matrizes de diversas montadoras de automóveis não tiveram do que reclamar de suas subsidiárias brasileiras em 2011. Os dados estão fresquinhos, foram divulgados pelo Banco Central na última terça-feira (24): a indústria automotiva no Brasil foi o setor que mais remeteu dinheiro ao exterior no ano passado, à frente até de bancos e empresas de telecomunicações, que ficaram com o segundo e terceiro lugares, respectivamente. Não se trata de números frívolos: foram os próprios fabricantes de veículos que registraram junto ao $\mathrm{BC}$ remessas de lucros e dividendos no total de US\$5,58 bilhões, o maior valor de todos os tempos, equivalente a $19 \%$ de todas as operações desse tipo no ano no Brasil e 36\% superior aos US\$4,1 bilhões de 2010. Não por acaso, as remessas recordistas de lucros e dividendos das montadoras instaladas no país aumentaram justamente no momento em que as matrizes mais sofrem nos mercados maduros de Europa e América do Norte, e por isso precisam sustentar seus resultados financeiros com o caixa das subsidiárias em países emergentes. (Kutney, 2012, grifos nossos)

Neste contexto, é perceptível que, com a mundialização do capital, há um simultâneo enfraquecimento das nações com consequências profundas para a instituição republicana. A República se mantém centralmente com base no binômio Estado-nação; atualmente, com a desnacionalização, sobra intacto apenas o Estado ou, para alcançar maior precisão, o que se mantém intacto é o aparelho 
do Estado, que neste contexto se torna um instrumento de produção. Se assim se pode argumentar, a República e sua burocracia operante tende a seguir a mesma linha de continuidade. Esta é uma consistente hipótese, porque mais de 60 países, que seguiram a receita do Consenso de Washington, realizaram uma reforma do aparelho do Estado.

O Banco Mundial produziu, na década de 1990, dois documentos com siglas iguais: PREAL. Um deles tratava-se do Programa de Reformas do Estado para a América Latina e o outro, tão importante quanto o primeiro, era o Programa de Reforma da Educação para a América Latina. As reflexões anteriores, somadas às análises dos documentos do Banco Mundial, nos possibilitam radicalizar nossa hipótese inicial sobre a instituição universidade pública. Nessa condição, ela se tornou também um instrumento de produção, daí suas novas funções sociais e econômicas.

Não se trata de mera coincidência o fato de termos, logo após a publicização do Plano Diretor para a Reforma do Aparelho do Estado em 1995, a promulgação da nova Lei de Diretrizes e Bases da Educação Nacional (LDB); alteração pela Coordenação de Aperfeiçoamento do Pessoal de Ensino Superior (CAPES) de seu processo de financiamento e avaliação de programas de pós-graduação, tornando-se mais uma das várias agências reguladoras que foram fundadas durante o governo de Fernando Henrique Cardoso; o início pelo Instituto Nacional de Estudos e Pesquisas (INEP), neste mesmo período, de suas variadas formas de avaliação, à época o "provão"; e, em seguida, a mudança pelo Conselho Nacional de Desenvolvimento Científico e Tecnológico (CNPq) de sua política de financiamento, outrora, de "demanda livre" para o financiamento de pesquisa por meio de editais, priorizando as áreas científicas que estavam relacionadas com os ramos industriais mais importantes para a política industrial e de comércio exterior. Além disso, as conferências de CT\&I passaram a ocupar lugar de destaque entre os eventos internacionais organizados pelo Estado, com apoio da Sociedade Brasileira para o Progresso da Ciência (SBPC) e da Academia Brasileira de Ciências (ABC), especialmente.

Tendo em vista a consistência da análise introdutória que aqui se fez no espaço de um artigo, é importante buscar o lastro teórico que nos orienta. Até este ponto do texto buscou-se indicar como a predominância financeira se expressou no Brasil na sua particularidade, para no próximo item indicar os principais traços do movimento que provocou mudanças institucionais como a do Estado e da universidade pública no Brasil. Esse movimento que se realiza especialmente durante os últimos vinte anos teve consequências estruturais para o trabalho como um todo. Num regime de predominância financeira o ciclo de movimentação do capital portador de juros é predominante e, distintamente dos demais ciclos, tem dupla dimensão: econômica e jurídica. Posto isto, esse ciclo joga peso e comprime os demais ciclos, produzindo uma intensa movimentação do capital em funções que, por sua vez, impõe a intensificação do trabalho no âmbito do ciclo de produção real de valor e em todos os setores que a ele se vinculam.

Em contrapartida, na predominância financeira o dinheiro desaparece quase totalmente na sua forma concreta num movimento de autonomização das formas 
verdadeiramente sociais que assume, produzindo o ápice do fetichismo da mercadoria dinheiro e da alienação do trabalhador.

Leda Paulani (2009, p. 12) analisa este movimento e, para avaliar como o crédito se autonomiza da produção de valor, recupera os passos anteriores deste movimento, partindo do valor de uso da mercadoria:

Para analisar esse quarto movimento [de autonomização do crédito em relação à produção de valor], é interessante fazer um retrospecto da totalidade do processo até aqui descrito: com o dinheiro, posto como equivalente geral, [1] o valor se autonomiza do valor de uso, mas internaliza no dinheiro a tensão que constitui a mercadoria entre a generalidade abstrata do valor que ela porta e a concretude do valor de uso que sustenta esse valor (e que também determina a mercadoria); [2] como meio de circulação, o dinheiro se autonomiza do concreto que a medida do valor requer, mas internaliza no meio de circulação a tensão entre abstrato e concreto constitutiva da medida do valor (que aparece como a exigência de que a medida do valor se apresente como padrão de preços); [3] como meio de pagamento, o meio de circulação se autonomiza da própria circulação, mas internaliza no meio de pagamento a contradição constitutiva do meio de circulação entre sua natureza abstrata e imaterial (que aponta logicamente para o dinheiro inconversível) e a materialidade da circulação a quem ele serve. [4] Ora, com o desdobramento do dinheiro (já plenamente constituído) em sua figura de crédito, o processo de acumulação se autonomiza da produção e realização da mais valia, mas internaliza no crédito a contradição constitutiva desse processo entre o impulso lógico de valorizar indefinidamente o valor em geral e a dependência que essa valorização tem da produção de riqueza real (ou seja, que tem o valor de uso por conteúdo) [Lembro aqui que o valor de uso é fruto do trabalho humano sob a égide do valor. Isto consiste na contradição de todo este processo.].

É interessante indagar sobre a primeira determinação do valor com que Paulani inicia o movimento. Trata-se do valor de uso. Cabe questionar qual tensão põe-se nesta determinação? Qual contradição o valor de uso carrega e transfere para o valor? Trata-se da tensão homem natureza que, superada através do trabalho, é fundante para a construção do ser social. Para a execução do trabalho, o ser humano produz os meios para realizá-lo: o conhecimento, a linguagem, as ferramentas, a ciência, a tecnologia, as normas sociais, o Direito, o Estado, as instituições etc. Ele produz uma esfera de mediação que é sua cultura, e por meio de sua incorporação e objetivação no trabalho o ser humano produz a si mesmo e ao gênero a que pertence. Desta forma, pretende-se mostrar neste movimento como o ser social através da cultura vai se complexificando neste movimento de mudanças das formas sociais do dinheiro e como o ser social passa a estar cada vez mais distanciado da dimensão verdadeiramente humana de seu trabalho produtor do valor de uso. Isto pode ser visto como o processo de alienação própria do capitalismo que se vai acentuando. Estes são os supostos que fundam a construção deste texto e é aqui indicado para mostrar como a expressão da predominância financeira no Brasil produziu não 
somente a intensificação do trabalho e a precarização de suas relações, mas, também, como se intensificou as condições sociais objetivas da produção da alienação no trabalho qualquer que seja a natureza que ele tenha. Daí o intenso processo nas reformas das instituições republicanas, entre elas a universidade pública.

Ricardo Antunes (1999, p. 122, grifos nossos), também orientado pelos escritos de Marx, escrevia o que pesquisamos nas universidades:

Liderada pelo capital para expandir-se, mas sendo em última instância prisioneira da necessidade de subordinar-se aos imperativos do processo de criação do valor de troca, a ciência não pode converter-se em principal força produtiva, em ciência e tecnologia independentes, pois isso explodiria, faria saltar pelos ares a base material do sistema de produção do capital. Mas, mesmo reconhecendo o hiperdimensionamento assumido pela ciência no mundo contemporâneo, o conhecimento social gerado pelo progresso científico tem seu objetivo restringido pela lógica da reprodução do capital. Impossibilitado de instaurar uma forma societal que produza coisas úteis com base no tempo disponível, resta à cientifização da tecnologia adequar-se ao tempo necessário para produzir valores de troca. A ausência de independência frente ao capital e seu ciclo reprodutivo a impede de romper esta lógica.

$\mathrm{Na}$ conjuntura de predominância financeira, esse movimento agudamente mostrado por Antunes impõe ao Estado e à universidade pública o que acontece na economia mundializada; o ciclo do capital financeiro comprime os demais e afeta a universidade pública no processo que se procurou investigar - a intensificação do trabalho do professor e sua respectiva alienação em relação ao seu próprio trabalho.

\section{A CONTÍNUA REFORMA DO APARELHO DE ESTADO E DA UNIVERSIDADE PÚBLICA NO BRASIL}

No contexto delineado no item anterior, o país experimenta uma radical transformação, e as universidades públicas são colocadas em posição estratégica. A autonomia universitária, especificamente a científica, e a indissociabilidade entre ensino, pesquisa e extensão gradativamente passam a ter sua sustentação numa equação em que a demanda econômica delineada torna-se a diretriz das investigações, cabendo ao governo criar as condições de financiamento e de reconstrução da cultura institucional da universidade pública, para que a universidade se transforme na agência executora de tais demandas, sobretudo na área de CT\&I.

No livro Novas faces da educação superior no Brasil (Silva Júnior; Sguissardi, 2001), mostrou-se que, em seminário sobre reforma constitucional sob o patrocínio da Presidência da República, Luiz Carlos Bresser Pereira - que futuramente seria ministro titular do Ministério da Administração Federal e da Reforma do Estado (MARE) - defendia a tese de que o Estado moderno, social-democrata, se materializaria especialmente a partir de 1995 com o Plano Diretor para a Reforma do Estado. É com base nele que se torna possível entender as mudanças e reformas que passaram a ser experimentadas pela universidade, sobretudo nas atividades de pesquisa. 
A constituição do setor de serviços não exclusivos do Estado permitiu a produção de um arcabouço jurídico que trouxe em seu núcleo a racionalidade da reforma do aparelho do Estado tal como percebida pelo ex-ministro Bresser Pereira, que vai ter na naturalização do fundo público pelo capital o marco deste processo (Sguissardi; Silva Júnior, 2009).Esta poderia ser a origem da construção da nova cultura institucional da universidade pública.

Francisco Oliveira (1999) escreve com clareza sobre este movimento no contexto do regime de predominância financeira, em que o Estado fica refém do capital fictício acionário, posto que deve administrar sua dívida interna por meio da emissão de obrigações do Tesouro Nacional. A subserviência financeira tem neste fato seu pecado original (idem, p. 56-57).

Assim, como escreveu Oliveira (2001,p. 3), "a reforma do Estado produziu a matriz política, teórica e ideológica para a reforma das demais instituições [republicanas]”. Do ponto de vista da economia política, isto significa a do processo que vai reposicionar a universidade pública a serviço da valorização do capital. Isto é, dava-se o primeiro e decisivo passo para a mudança de sua cultura institucional e para a origem de um novo paradigma de produção de conhecimento e das novas funções sociais e econômicas da universidade pública, com severas consequências para o trabalho do professor universitário.

Decorre deste cenário a base para futuras ações jurídicas, em especial do Executivo, para a mudança substancial da cultura institucional da universidade pública, bem como do conteúdo e forma do trabalho do professor universitário para a profunda mudança de toda cultura no país ao desenvolver as forças produtivas e mudar profundamente os meios de controle e regulação sociais, com consequências negativas para a universidade: a produção de conhecimentos no âmbito institucional, nacional e internacional. Trata-se da universidade pública assumida, tal qual o aparelho de Estado, como instrumento de produção em favor do capital produtivo amalgamado ao financeiro sob o atual regime de acumulação.

\section{A PÓS-GRADUAÇÃO NAS UNIVERSIDADES FEDERAIS: EXPANSÃO E PRODUÇÃO DE CONHECIMENTO}

O investimento em inovação tecnológica e ciências aplicadas, sugerido a partir da LDB 9.394/96 pelas Leis da Inovação Tecnológica e da Parceria Público-Privada, entre outros instrumentos jurídicos, amplia e valida a formação dos profissionais e o trabalho de professores-pesquisadores em seus programas institucionalizados nas mais diversas áreas do conhecimento, especialmente na pós-graduação, pela reorganização dos programas em sua forma de gestão do trabalho do professor em face da relativa subordinação à CAPES.

Esta agência, fundada nos anos de 1950 com o objetivo de capacitação do pessoal de ensino superior, após se constituir, por décadas, em um órgão do Estado para financiamento e avaliação da pós-graduação, acentuou, a partir de 1997, sua função reguladora com o objetivo de organizar e reorganizar não somente os programas, mediante seu modelo de avaliação, mas todo o sistema, tornando-se, assim, uma efetiva "agência reguladora da pós-graduação brasileira". Este fato, segundo a 
CAPES, justificava-se pela necessidade de formação de pesquisadores e da criação de um sistema de pós-graduação mais produtivo, regulado e flexível, para orientar e reorientar suas pesquisas e a produção de conhecimento.

A expansão da pós-graduação no Brasil, em face da silenciosa reforma universitária com sua origem na reforma do Estado, atinge proporções maiores quando comparada com semelhante movimento realizado na graduação, conforme se pode observar na Tabela 1, que toma como exemplo para esta afirmativa os sete Institutos Federais de Ensino Superior (IFES) de diferentes características da região Sudeste do Brasil, ${ }^{2}$ foco de investigação dos últimos trabalhos de Sguissardi e Silva Júnior (2009) e Silva Júnior et al. (2011):

Tabela 1 - Evolução do número de matrículas de Graduação presencial, Mestrado e Doutorado - Sete IFES da região Sudeste - 1995-2010

\begin{tabular}{|c|c|c|c|c|c|}
\hline IFES & Ano & Graduação & $\Delta \%$ & $\begin{array}{l}\text { Mestrado e } \\
\text { Doutorado }\end{array}$ & $\Delta \%$ \\
\hline \multirow{2}{*}{ UFMG } & 1995 & 17.747 & \multirow{2}{*}{56,9} & 2.567 & \multirow{2}{*}{124,3} \\
\hline & 2010 & 27.850 & & 5.758 & \\
\hline \multirow{2}{*}{ UFF } & 1995 & 15.967 & \multirow{2}{*}{63,0} & 1.180 & \multirow{2}{*}{169,6} \\
\hline & 2010 & 26.029 & & 3.181 & \\
\hline \multirow{2}{*}{ UNIFESP } & 1995 & 1.232 & \multirow{2}{*}{314,4} & 1.822 & \multirow{2}{*}{37,4} \\
\hline & 2010 & 5.106 & & 2.504 & \\
\hline \multirow{2}{*}{ UFU } & 1995 & 9.360 & \multirow{2}{*}{82,4} & 358 & \multirow{2}{*}{364,5} \\
\hline & 2010 & 17.072 & & 1.663 & \\
\hline \multirow{2}{*}{ UFES } & 1995 & 9.771 & \multirow{2}{*}{106,5} & 280 & \multirow{2}{*}{453,6} \\
\hline & 2010 & 20.181 & & 1.550 & \\
\hline \multirow{2}{*}{ UFJF } & 1995 & 7.025 & \multirow{2}{*}{78,8} & $-{ }^{2}$ & \multirow[b]{2}{*}{$\cdots$} \\
\hline & 2010 & 12.560 & & 1088 & \\
\hline \multirow{2}{*}{ UNIRIO } & 1995 & 4.147 & \multirow{2}{*}{68,4} & 155 & \multirow{2}{*}{211,6} \\
\hline & 2010 & 6.985 & & 483 & \\
\hline \multirow{2}{*}{ TOTAL } & 1995 & 65.249 & \multirow{2}{*}{77,4} & 6.362 & \multirow{2}{*}{155,1} \\
\hline & 2010 & 115.783 & & 16.227 & \\
\hline
\end{tabular}

Fonte: GEOCAPES; UFES/PROPLAN (1995-2010), UFF/PROPLAN (1995-2010), UFJF/PROPLAG (1995-2010), UFMG/PROPLAN (1995-2010), UNIFESP/DCF (1995-2010), UNIRIO/PROPLAN (1995-2010), UFU/PROPLAD (1995-2010).

Elaboração do Grupo de Pesquisa Economia Política da Educação e Formação Humana (GEPEFH).

Notas:

${ }^{1}$ - Em virtude da inexistência desses dados nas bases de dados do GEOCAPES (1995, 1996 e 1997), foram utilizados os dados dos Relatórios de Gestão das respectivas IFES.

2 - Dado não disponível no Relatório de Gestão.

2 As IFES investigadas na região Sudeste foram: Universidade Federal do Estado do Rio de Janeiro (UNIRIO); Universidade Federal de Juiz de Fora (UFJF); Universidade Federal do Espírito Santo (UFES); Universidade Federal de Uberlândia (UFU); Universidade Federal de São Paulo (UNIFESP); Universidade Federal Fluminense (UFF); e Universidade Federal de Minas Gerais (UFMG). 
Apresenta-se na Tabela 1 os dados no intervalo de 1995 (marco no processo de reforma do Estado) e 2010 (dados do último senso do INEP) para demarcar a evolução pontual deste período na expansão das matrículas na graduação e pós-graduação. Observa-se, com exceção da UNIFESP, que todas as demais instituições apresentam um percentual menor de crescimento na graduação e maior na pós-graduação, com destaque para aumentos significativos de evolução, como a UFU $(364,5 \%)$ e a UFES (453,6\%). No caso da UNIFESP, que apresenta um percentual reduzido de crescimento na pós-graduação $(37,4 \%)$ e evoluído na graduação $(314,4 \%)$, é entendido pelo histórico peculiar desta instituição, que mesmo sendo de médio porte, mantém as atividades de pós-graduação desde 1970 com os primeiros programas stricto sensu, ainda como Escola Paulista de Medicina, e em 1995 já mantinha 36 cursos de mestrado e 37 de doutorado.

A expansão do número de matrículas entre graduação $(77,4 \%)$ e pós-graduação $(155,1 \%)$ demonstra a parte mais visível dos impactos recebidos no trabalho do professor que contraditoriamente na última década (2000-2010) apresenta na função docente (em exercício) um aumento de apenas 30,8\%, nos sete IFES (INEP, 2001; 2011).

A leitura destes dados sobre a produção de conhecimento e trabalho docente permite destacar a importância da expansão da educação superior, especialmente na pós-graduação, demonstrando um processo de consolidação histórica da atual tendência mundial de investimentos em CT\&I. Os dados demonstram que o Brasil, ao longo de quase duas décadas, vem transformando tais investimentos em políticas de Estados com graves consequências para os objetivos da instituição universitária, para sua cultura institucional e, sobretudo, para o trabalho docente.

\section{O TRABALHO DOCENTE: EVOLUÇÃO, INTENSIFICAÇÃO E ALIENAÇÃO}

A universidade está profundamente mudada em sua estrutura, organização e gestão. Formas de gestão político-institucionais estão postas desde seu exterior, bem como a avaliação se realiza por resultados e sua acreditação, pela "relevância de sua pauta de pesquisa". Existem três instituições estatais a induzirem a reconfiguração da pós-graduação no país: 1) o $\mathrm{CNPq}^{3}$ com seus convênios e editais indutores de pesquisa aplicada em busca da produtividade do capital; 2) a CAPES, que regula um sistema de pós-graduação e cada programa com o mesmo objetivo do CNPq; e 3) a gestão do fundo público voltado para a produção de valores que, em última instância, conduz a reforma universitária no cotidiano, tendo no professor o seu principal ator.

3 Neste contexto, vale destacar que até o ano de 1999 os projetos de pesquisa eram encaminhados ao CNPq através da "Demanda Livre", isto é, não havia editais estabelecendo prioridades para as áreas de conhecimento, apesar da existência dos Fundos Setoriais. A partir do ano 2000, passou a existir uma política de financiamento com o estabelecimento de prioridades para áreas do conhecimento orientadas pela política industrial, por sua vez desenhada conforme a política econômica brasileira. 
Como se procurou mostrar, o Estado reorganiza a pós-graduação de forma mediada pela CAPES e pelo CNPq. Estas agências buscam, de forma articulada, fazer da pesquisa um elemento central para a produção de um conhecimento orientado para a valoração do capital. Porém, quando se trata do setor produtivo, o fundo público naturalizado pelo capital busca produzir novas tecnologias de processo e de produto que agreguem mais valor aos produtos que serão comercializados no mercado internacional ou nacional. Este processo transcende a produção e tem em seu centro as relações que as corporações mundiais estabelecem com outras empresas, bancos, agências multilaterais, Estados e instituições estatais, neste caso particular, as universidades.

As novas formas e conteúdos do trabalho do professor acentuam-se nas universidades federais a cada ano ou triênio nas avaliações da CAPES, e há um aprofundamento das novas possibilidades de produção de pesquisas financiadas, via parcerias com o setor público e privado e com agências de fomento de diversas ordens, auxiliado pelo trabalho das fundações de apoio institucionais. Neste processo, as relações de produção permeiam o trabalho do professor e o alienam de seu trabalho, do produto dele e, portanto, de si mesmo.

Em face disso, a educação é demandada pelo capital a reformar-se, assim como, e primeiramente, o Estado nacional. Para o que se está analisando, a pós-graduação passa a ocupar um espaço central e mais relevante para o Estado, posto que, no país, o lugar em que o conhecimento é desenvolvido com maior consistência é o dos níveis pós-graduados das universidades (cf. Sguissardi; Silva Júnior, 2009). Esta condição estabelece no cotidiano das universidades processos de gestão em que os professores que não pertencem aos quadros da pós-graduação almejam muito entrar para este nível por conta das melhores condições de oportunidades de financiamento e possibilidade de consultorias, alienando-se desde o início. Em contrapartida, os que estão inseridos na pós-graduação correm atrás de publicações, financiamentos para pesquisas em geral aplicadas, consultoria, construindo na iniciação científica, na extensão e no ensino semelhante cultura. Por esta via, as aulas são redirecionadas, o espaço da iniciação científica se reestrutura e o processo formativo dos alunos da graduação é permeado por semelhantes valores. Na pós-graduação, na sua grande maioria, os professores são empreendedores e orientam seus estudantes desta mesma forma, razão pela qual a pós-graduação é o lugar por excelência da alienação do trabalho do professor. A cultura mediadora para a reprodução do gênero humano permeia todos os poros institucionais. E, em razão do novo lugar e funções sociais e econômicas da universidade, este processo acentua-se como nunca.

Diante de estrutural demanda e suas consequências, existe um processo de evolução na qualificação acadêmica dos professores, a exemplo da amostra do Sudeste, cuja evolução de doutores entre 1995 e 2009 cresceu mais de 850\%, com diminuição significativa de professores com apenas o título de graduação (média de 156\%) e de mestres (média de 147\%).

Contudo, é preciso considerar-se que a diferença do número de professores doutores entre 1995 e 2009 também decorre da determinação da LDB 9.394/96 
quanto à titulação mínima para atuação na educação superior. Tal preceito jurídico também estimulou a expansão no nível de pós-graduação necessário para sua consolidação.

No atual contexto, visível por meio dos dados acima, é importante destacar dois pontos correlatos: o primeiro consiste no formalismo abstrato da carreira do professor universitário cada vez mais qualificado (por isso a exigência de títulos cada vez mais altos), cuja contratação está para além do exercício da docência, pesquisa e extensão, mas que, em face das políticas públicas derivadas da reforma do Estado e da educação superior, vê-se compelido à complementação salarial e à ideologia do produtivismo acadêmico, produzida pela burocracia estatal e, hoje, um dos pilares centrais da cultura da instituição universitária (idem).

O segundo ponto consiste na produção da materialidade institucional também inserida no chamado produtivismo acadêmico em suas múltiplas formas de concretização: da produção de muitos artigos, seções de livros, mas de forma mais acentuada na relação direta com o capital. Esta ideologia do produtivismo acadêmico origina-se no Estado, com mediação da CAPES e do CNPq, acrescidos da Financiadora de Estudos e Projetos (FINEP) e do Banco Nacional de Desenvolvimento Econômico e Social (BNDES), entre outros. O produtivismo acadêmico apresenta-se como moeda de troca no Currículo Lattes (CV-Lattes), ${ }^{4}$ que se torna o portfólio dos professores para concorrerem em editais públicos ou oferecerem seus serviços de consultoria junto às corporações mundiais ou empresas estatais (idem).

A objetivação da evolução do produtivismo e o pragmatismo que a ele está associado, dominante no meio acadêmico, são expressivos na evolução da produção intelectual dos docentes da pós-graduação avaliada pela CAPES a cada triênio. Pode-se exemplificar esta afirmativa considerando-se apenas cinco cursos de duas instituições, de diferentes históricos e contextos, como a Universidade Federal Fluminense (UFF) e Universidade Federal de Minas Gerais (UFMG), que apresentaram em dez anos (1998-2008) uma evolução percentual significativa na Produção Intelectual (PI) avaliada pela CAPES (que inclui produção de livros, artigos, capítulos e trabalhos completos publicados em anais de eventos). Identifica-se que na UFF a média de evolução foi de 24 PI (1998) para 254 em 2008, um aumento de mais de 950\%. Na UFMG passou de 64 PI (1998) para 177 em 2008, representando uma variação de 176,5\%. Embora apresentem evolução diferenciada, respeitados os contextos institucionais e históricos, a evolução de ambas é resultado do processo acelerado e competitivo de produção intelectual no impulso dos critérios avaliativos da CAPES, apresentando um quadro de evolução crescente a cada avaliação trienal.

4 O Currículo Lattes consiste no portfólio de muitos doutores, formados depois de implantado o novo Modelo Capes de Avaliação, em 1996-1997, incentivando-os a correrem atrás de pós-doutoramentos, de publicações, de bolsas de produtividade, de participação em congressos bem classificados academicamente, isto com o objetivo de fazer caminhar a "nova universidade", sem saberem bem para onde ela caminha. 
Podemos supor fortemente que, embora a produção de conhecimento seja de natureza imaterial, seu financiamento e os tempos e controles para sua realização são impostos pelo setor produtivo e pela necessária produção de valor segundo a racionalidade da produção de mercadorias e as relações sociais de produção. $\mathrm{O}$ produto da pesquisa aplicada será de pronto incorporado à organização privada. Esta é uma das razões pelas quais as corporações mundiais, mais do que as de capital nacional, têm-se aproveitado das universidades brasileiras. Vejam-se os clientes do Laboratório Nacional de Luz Síncroton, o convênio da Microsoft com a Fundação de Amparo à Pesquisa do Estado de São Paulo (FAPESP), dentre outros exemplos. Novamente, a punção de conhecimentos se processa aqui em larga escala e intensifica o trabalho do professor, além de impor a cultura do produtivismo acadêmico, que tem na pós-graduação seu polo irradiador da nova cultura institucional para toda universidade pública, isto é, a pós-graduação torna-se a origem da silenciosa reforma universitária que vem se operando desde a reforma do aparelho do Estado em 1995.

No âmbito do arcabouço jurídico legal, podemos citar como marcos regulatórios importantes que caracterizam a atual política de CT\&I: a criação dos Fundos Setoriais (1999); a Lei de Inovação Tecnológica (lei federal n. 10.973, de 2 de dezembro de 2004), que estabelece medidas de incentivo à inovação e à pesquisa científica e tecnológica no ambiente produtivo, com vistas à capacitação e ao alcance da autonomia tecnológica e ao desenvolvimento industrial do país.

Como se pode notar do que se expôs até este momento, todas as ações políticas colocam o fundo público com o objetivo de aumentar a produtividade brasileira e, com isso, o capital produtivo nacional para lastrear o capital financeiro nacional e mundial. Mas, sobretudo, de mostrar ao mundo como o país realiza suas políticas para transformar uma economia com alta potência de acumulação em valor efetivo, de um lado; de outro, a que de fato tornou-se uma excelente praça bursátil para o mercado mundial de capitais. Isto parece acentuar a consistência de nossa hipótese de que o aparelho de Estado e a universidade pública tornaram-se instrumentos de produção no contexto do regime de predominância financeira. Nesta fase do capitalismo, o Brasil e os demais países do Agrupamento Brasil-Rússia-Índia-China-África do Sul (BRICS), considerando as assimetrias deste conjunto de países, são o centro financeiro para onde se dirige o investimento estrangeiro direto. Isto parece dar-se predominantemente por meio da CT\&I das novas formas de organização e gestão do trabalho humano que daí decorre, segundo a política industrial do Ministério de Ciência, Tecnologia e Inovação (MCTI) e do Ministério de Desenvolvimento, Indústria e Comércio Exterior.

Em pesquisa recente (Silva Júnior et al., 2011) sobre os significados do trabalho do professor, financiada pela FAPESP, tendo como amostra sete IFES do Sudeste, citadas neste ensaio, foi possível revelar pelo trabalho de campo (análises in loco e entrevistas) o quanto a conjuntura político-institucional da universidade modifica e intensifica a alienação do professor sob seu próprio trabalho e conduta.

Ao voltar-se às entrevistas (da primeira fase da pesquisa) e mesmo durante novas entrevistas que foram feitas na referida pesquisa, nota-se que a fruição ou 
"momento de suspensão" sempre se encontrava presente de formas variadas para cada sujeito em razão de sua história de vida.

A vida cotidiana é presa ao senso comum e à superficialidade extensiva. A estrutura da vida cotidiana produz a potência para a alienação humana. ${ }^{5} \mathrm{O}$ ser social é um ser que dá respostas imediatas aos problemas que o cotidiano lhe põe. Suas respostas se encontram, portanto, neste mesmo plano, no plano das aparências. No plano da "vida como ela é". Contudo, esse mundo pode ser visto próximo de como ele de fato é objetivamente, e aí a dialética de Lukács pode mostrar este mundo. Isto exigiria a suspensão da fragmentação e da heterogeneidade do cotidiano aparente, o que implicaria a incorporação da forma de ser por meio da qual o ser humano, na sua singularidade, alcançasse a experiência do humano genérico, não com "todas as suas forças, mas com toda a sua força", num processo de articulação de todos os fenômenos que constituem seu contexto, que se mostra aparentemente em um fragmento aleatório da realidade. Este processo poderia conduzir à crítica do cotidiano alienado e à compreensão da totalidade do fragmento, numa suspensão do cotidiano imediato, de forma que o indivíduo no seu ser singular já sentiria e viveria o cotidiano de maneira autocompreensiva.

O contexto que the cobra resposta imediata já não seria mais um fragmento aleatório da realidade, mas algo em que ele viveria, sentiria e, assim, entenderia suas relações com ele, bem como as razões de suas necessidades e as práticas que põem em movimento em face destas necessidades. Este momento é denominado pelo filósofo húngaro como um momento de suspensão do cotidiano. Lukács (1979) indica três atividades humanas como possíveis de serem as principais vias para a suspensão: o trabalho criador (não alienado, portanto), a ciência (aqui tomada como processo de desantropomorfização da realidade) e a arte (um processo antropomorfizador, referente à construção da autoconsciência humana).

Entretanto, especialmente em razão da cultura atual dos IFES, também se apresentava com grande ênfase a alienação do professor em relação ao seu trabalho, ao produto de seu trabalho e, especialmente, em relação a si mesmo. Casos em que o sofrimento aparecia como conteúdo da linguagem dos sujeitos da pesquisa. Isto é, quanto maior a distância entre o conhecimento do ser objetivo em si e da representação de si na consciência, maior o grau de alienação. Ao mesmo tempo, e no mesmo processo, quanto menor era esta mesma distância, mais predominante na contradição era a suspensão e menor a alienação.

$5 \mathrm{Na}$ mesma linha das reflexões ontológicas de Lukács, considera-se neste texto que a alienação é primariamente um fenômeno histórico, social e objetivo. Portanto, o tratamento da alienação no trabalho do professor não significa, de forma alguma, considerar que esse fenômeno tenha origem na consciência do indivíduo. Razão pela qual se recorre à busca de mostrar as articulações entre a predominância financeira, e o distanciamento do ser social da dimensão verdadeiramente humana de seu trabalho ao se analisar o movimento do valor e suas formas acentuadamente sociais através do texto de Paulani (2009). 
Neste relato sobre as políticas de avaliação e financiamento do trabalho do professor, o movimento contraditório entre alienação e suspensão apresenta-se mostrando, de um lado, a heterogeneidade dos professores na instituição, de outro, a adaptação em razão de um individualismo imediato que ofusca e fetichiza o trabalho docente em razão da racionalidade econômica que permeia a universidade pública. Cauteloso, o professor fala sobre o tema:

Professor: Eu acho que o tema continua sendo e será, realmente, muito interessante. Eu acho que enfrentar essas questões, elas são as questões basilares pros nossos, pra nossa vida. E há vários olhares sobre isso. Tem o olhar que é esse olhar que você está buscando, que é um olhar mais crítico e tudo mais, um olhar mais reflexivo, mas tem outro olhar também, que aí eu não sei né? Eu estou falando pra você, que é o olhar de alguém que acha que está tudo legal. Quer dizer, alguém aí que se adaptou ao sistema, está se dando bem no sistema [...]. Do ponto de vista do seu individualismo e tal, ele se encontra satisfeito nisso. Eu acho que esse olhar, eu acho que em algum momento você deveria observar também esse olhar. Porque existe isso, existem companheiros nossos, por exemplo, que se identificam claramente com esse tipo de coisa. E aí eu vejo um grande motivo pro estudo da questão das vaidades humanas mesmo. Eles pertencem às academias, estão lá ditando as políticas, se sentem integrados a esses grupos e às próprias agências, as próprias políticas governamentais, em grande parte, ela é sustentada, desenvolvida e mantida pelos próprios professores ou pesquisadores que se assentam nesses grandes conselhos. A CAPES, por exemplo, na verdade é tomada, em grande parte. Na política de governo da CAPES são colegas nossos, parceiros nossos, etc. E aí eu acho que a vaidade humana, lógico que a gente vai envelhecendo e vai caindo mais nessas pessoas mais subjetivas, mais do comportamento. (E1 apud Silva Júnior et al., 2010, p. 165)

O depoimento do docente indica que a investigação em curso tem hipóteses críticas, ou nas palavras acima, "reflexivas". Igualmente, há a afirmação da existência de outra perspectiva de análise de colegas professores que estariam em conformidade com as políticas de avaliação, financiamento e paradigma de pesquisas oficiais. Seriam professores que se encontrariam satisfeitos com a cultura atual da instituição universitária. Neste ponto, o professor entrevistado indica um dos rasgados traços dos processos institucionais que produzem a sociabilidade de seus colegas (idem).

Esta expressão reiterada ganha forte sentido para o depoente e parece indicar a vaidade como uma característica estrutural e imanente ao ser humano. Nela residiria a base para a identificação do ser social pesquisador com a cultura institucional, com base nela haveria um prazer no atingimento das metas exigidas pelos órgãos de financiamento e a produção de determinado conhecimento induzido pelo financiamento a ditar o que deveria ser produzido pelos pesquisadores. Ainda assim, ele adaptar-se-ia ao sistema produzido pelo pacto institucional. $\mathrm{O}$ depoente faz a crítica à adaptação ativa dos colegas ao modelo vigente, ao mesmo tempo parece 
naturalizar sua própria explicação, sugerindo que com a idade os seres humanos tenderiam a explicar as razões para tudo de forma psicologizante.

A consideração das transformações históricas da alienação com base no complexo categorial produzido no relatório parcial que mostra as relações indissociáveis e contraditórias entre a sociabilidade e a subjetividade (idem) nos remete ao trabalho do professor e às mudanças na cultura institucional objetivadas nas práticas universitárias. As mudanças na educação e na universidade ocorridas na última década no Brasil provocaram alterações estruturais no trabalho do professor, observáveis de forma explícita e desenvolvida na cotidianidade das atividades do professor da pós-graduação e reveladoras da predominância da alienação em relação à suspensão possível de compreender-se graças ao entendimento do processo induzido pela predominância financeira. Destaca-se que esta mesma forma de organização da produção da vida humana se expressa no PNPG 2011-2020, indicando o devir da pós-graduação, da consolidação da atual cultura da instituição republicana universidade pública e do trabalho docente. A pós-graduação, como bem mostrado em Sguissardi e Silva Júnior (2009), tornou-se o polo irradiador da silenciosa reforma universitária, agora, com o PNPG 2011-2020, a reforma tende a se institucionalizar e a natureza do trabalho docente também, acentuando os processos alienantes que já se põem nas práticas acadêmico-científicas e gestoras. A alienação parece consistir no traço central do trabalho do professor, doravante com consequências previsíveis, que se poderá verificar com muita evidência nos programas em uma pesquisa de campo.

\section{O NOVO PNPG 2011-2020: AVALIAÇÃO INTENSIFICADA, EMPREENDEDORISMO E INTERNACIONALIZAÇÃO DA PÓS-GRADUAÇÃO}

O exposto até aqui faz-nos analisar as perspectivas para os próximos anos no que diz respeito ao trabalho docente na pós-graduação brasileira. Optamos por avaliar o recém-lançado PNPG 2011-2020 que consolida nossa hipótese de que a universidade tornou-se linha de continuidade do Estado, um instrumento de produção direcionado para o capital financeiro mundializado. De sua análise, destacamos três pontos-chave que acreditamos ser cruciais para o entendimento histórico de como a racionalidade mercantilizada - já anunciada como potência no Plano Diretor de Reforma do Aparelho do Estado, que previa mudanças-chave nas principais instituições republicanas do país - põe-se na história recente não mais como potência, mas como fato concreto.

Desse modo, nossa pesquisa recém-concluída pela FAPESP, de todo um programa de pesquisa construído ao longo de aproximadamente 16 anos de trabalho, de pós-doutoramentos dirigidos pelas necessidades postas neste itinerário e sempre em diálogo com o Grupo de Trabalho de Política de Educação Superior da Associação Nacional de Pós-Graduação e Pesquisa em Educação (ANPEd) e, 
mais recentemente, com o projeto nacional sobre a expansão da educação superior, tomam concretude ao apresentar as novas orientações para o trabalho docente.

A análise do atual PNPG nos mostra com clareza solar o forte apelo educacional, na forma de política pública, com políticas diferenciadas para cada nível e modalidade de ensino. Destacamos o esforço por parte do governo federal pelo fomento à formação técnica para alunos de baixa renda, oriundos das escolas públicas, com destaque ao PRONATEC, com o objetivo de formação técnica e profissional dos trabalhadores e alunos do ensino médio. Programas de acesso ao ensino superior - com forte expansão das universidades públicas e privadas, sobretudo, por meio da modalidade educação a distância $(\mathrm{EaD})$ - em que destacamos o PROUNI e a expansão da Rede Federal de Educação Tecnológica com a previsão da criação regional de Institutos Federais de Educação, Ciência e Tecnologia por todo país com vistas a dar formação tecnológica adequada e mão de obra necessária ao crescimento econômico local. E, finalmente, a expansão do Santo Graal - a pós-graduação -, que conta com programas como Ciência sem Fronteiras, que busca promover a consolidação, expansão e internacionalização da CT\&I da competitividade brasileira por meio do intercâmbio e da mobilidade internacional para alunos de graduação e pós-graduação na forma de bolsas de estudos, com a finalidade de sugar, por meio da formação acadêmica e técnica, de parcerias e de intercâmbios institucionais, a tecnologia de sistemas educacionais e de pesquisas mais competitivos em países mais avançados no fomento ao trinômio CT\&I nas áreas consideradas prioritárias e estratégicas para o desenvolvimento econômico do país. Há ainda um incremento nas verbas da CAPES e do CNPq ao fomento de bolsas e de pesquisas, através de editais de apoio que privilegiam áreas tecnológicas e pesquisas fortemente vinculadas à Política Industrial Tecnológica e de Comércio Exterior (PITCE).

$\mathrm{A}$ análise do atual PNPG nos leva à potencial hipótese de que a autonomia universitária não passa de uma epifania. Todo o sistema de avaliação, classificação e orientação da pós-graduação brasileira induzem a um esgarçamento da autonomia universitária, estando a produção do conhecimento e a formação de nossos pesquisadores totalmente comprometidas "com o aumento do valor agregado de nossos produtos e a conquista competitiva de novos mercados no mundo globalizado" (Brasil, 2010, p. 37). Este plano parece fortalecer e concretizar uma política que há quase duas décadas já vinha se consolidando na tentativa de mudança na cultura universitária, nos seus objetivos, na formação de seus pesquisadores e que, apesar de ser recebida com resistência, vem sendo amplamente aceita pela geração de novos doutores que pouco a pouco vão assumindo as atividades de pesquisas e esvaziando o lugar da crítica. Três são as categorias mais importantes que podemos destacar numa leitura atenta deste plano: a avaliação intensificada, o empreendedorismo e a internacionalização da pós-graduação brasileira.

O fortalecimento desta cultura acadêmica propalada há mais de uma década e que comumente denominamos de "Modelo CAPES de Avaliação" está baseada em indicadores de excelência e, sob o pretenso discurso da necessidade de se imprimir um caráter social à pesquisa científica, revela uma face muito 
perversa para a autonomia científica do país: a burocratização da ciência brasileira, do conhecimento produzido na universidade que, por excelência, deveria ser o lugar da crítica e do debate livre. A concepção de ciência se altera e este processo tende a se acentuar, a se julgar pela análise do PNPG agora vigente. Marx Weber, em seu livro $A$ ciência como vocação, ao analisar o sistema universitário alemão e americano, já apontava para estas mudanças na forma de fazer ciência livre e por vocação em pleno século XIX.

O que estudamos neste Plano é a adoção de uma política de Estado que visa à criação, por meio de políticas públicas na forma de planos, programas como os já citados anteriormente, e de um arcabouço jurídico educacional que permite a integração de um Plano Nacional de Desenvolvimento Econômico e Social interligado a um Programa Nacional de Pós-Graduação, que convoca a universidade e sua estrutura acadêmico-científica, técnica e pedagógica a inserirem o Brasil num sistema econômico mundial e competitivo por mercados. Sua indução é realizada, no plano político-acadêmico, pela CAPES, que se torna a agência que realiza a análise nacional de qualidade e excelência da pós-graduação brasileira, num sistema que qualifica:

Avaliação da produção tecnológica e seu impacto e relevância para o setor econômico, industrial e social; através de índices relacionados a novos processos e produtos, expressos por patentes depositadas e negociadas, por transferência de tecnologia e por novos processos de produção que poderão dar uma vantagem competitiva ao país; incentivo à inovação através da adoção de novos indicadores, que estimassem o aumento do valor agregado de nossos produtos e a conquista competitiva de novos mercados no mundo globalizado. Um maior peso deveria ser dado a processos inovadores que refletiriam em maiores oportunidades de emprego e renda para a sociedade; fortalecimento das atuais atribuições dos órgãos superiores da CAPES, principalmente as referentes à avaliação, autorização de cursos novos e o seu recredenciamento, com vistas à manutenção do Sistema Nacional de Pós-Graduação; indução da pós-graduação, mediante constante atualização dos indicadores empregados, de modo a orientar a formação de recursos humanos e a pesquisa na direção das fronteiras do conhecimento e das prioridades estratégicas do país. (idem, ibidem)

Duas questões merecem destaque: primeiro, o papel centralizador e arbitrário da CAPES na figura do Estado, que por meio de critérios de excelência cria um ranking, impondo a estas instituições um selo de qualidade (idem, p. 127) e, em segundo lugar, a forte indução de pesquisas via financiamento e processos avaliativos na criação de uma nova sociabilidade científica brasileira - caracterizada de forma predominante pela aceitação, pelo não debate, pelo total descompromisso com pesquisas livres, por novos formatos e modelos de formação pós-graduada que diminui seus tempos de formação e fomenta mudança nos formatos dos programas com disciplinas que primam muito mais pela formação técnica em detrimento da 
epistemologia. Sem grandes opções aos programas, que se sentem compelidos a assumir tais características sob o risco de perda de credenciais, bolsas, verbas para pesquisas, dentre outros mecanismos.

Outro destaque essencial para nossa discussão consiste nas diretrizes desse sistema de pós-graduação para os próximos dez anos. Há um esforço de diferenciação institucional dos programas de pós-graduação stricto sensu. Há a indução no sentido da diminuição da entronização do modelo de universidade humboldtiana. A CAPES assumirá o papel de incentivar e conduzir, a despeito do pretenso desenvolvimento econômico e social do país, a formação "cada vez mais numerosa" para pós-graduandos voltados para atividades extra-acadêmicas, com destaque para o incentivo à criação de mestrados profissionais ainda incipientes no atual sistema.

No topo do sistema estão as universidades humboldtianas, conhecidas por patrocinarem a união indissolúvel do ensino e da pesquisa, com a pós-graduação à frente, servindo de modelo ou farol para o sistema. Porém, no primeiro mundo e no Brasil, elas são a minoria, apresentando toda sorte de distorções: trata-se de um conceito ou de um ideal, a exigir ajustes ao ser trazido para os dias de hoje e aplicado à realidade das instituições. Não obstante, elas existem e deverão ser cobradas nas avaliações por sua inserção internacional ou pela capacidade de oferecer cursos de padrão internacional. Ao lado das universidades públicas humboldtianas e de uma ou outra comunitária que integra aquele prestigioso rol, há as públicas não humboldtianas e as privadas, distinguidas entre as comunitárias e as não comunitárias, com menos vocação acadêmica e maior proximidade com o mercado e, por vezes, com o setor produtivo. Este conjunto de natureza diferente e complementar deverá responder por demandas e necessidades diferentes: num extremo, a necessidade de formar professores e pesquisadores voltados para o sistema de ensino e de pesquisa; noutro extremo, a necessidade de formar quadros e técnicos altamente especializados para os setores público e privado. Em consequência, será preciso criar mais de um sistema de avaliação e depurar diferentes critérios de teor acadêmico e não acadêmico, ajustados para as diferentes situações e necessidades, como no mestrado profissional. (idem, p. 128)

\section{PALAVRAS FINAIS}

As recomendações anteriormente descritas aventam a necessidade de um novo modelo de pós-graduação que não seja pesadamente teórico e acadêmico, com novos padrões de desempenho acadêmico e que acompanhe as mudanças por que passaram as principais nações, primando por uma formação técnica demandada pelas mudanças científicas e tecnológicas adequadas à nova base de produção capitalista - a predominância financeira. Estas parecem ser as novíssimas faces da universidade brasileira. Com base nestas diretrizes que está sendo construído o 
pacto científico e tecnológico nacional. Este processo de reposicionamento social e econômico da estrutura universitária acarreta mudanças que se concretizam sob a forma de intensificação do trabalho do professor, da acentuação do processo de precarização das relações de trabalho e da degradação das relações humanas na instituição universitária.

Este parágrafo final consiste na síntese deste texto, mas, também, na direção que se seguirá investigando o trabalho docente na pós-graduação na universidade que se transformou em instrumento de produção no processo histórico atual, em que o Brasil se tornou a plataforma internacional financeira do valor. Este fato atualiza as propostas e projetos para o país com base no dependentismo. Não importa atrelar o desenvolvimento brasileiro ao crescimento econômico do capital produtivo internacional, mas tornar viável segundo o capital financeiro mundializado, colocando o país numa frágil posição que o obriga a seguir a política financeira das grandes potências à custa de uma ainda maior exploração dos trabalhadores, como se pode notar com a aproximação da presidente Dilma Rousseff da primeira ministra Angela Merkel no que se refere à ajuda financeira à Europa e, em contrapartida, a aproximação de Rousseff da ministra de Estado Hillary Clinton, especialmente no que se refere à política bélica dos EUA - fato que mereceu elogios do primeiro ministro britânico David Cameron, recentemente, sugerindo que o Brasil já deveria estar no Conselho de Segurança da ONU. O Brasil cumpre historicamente sua identidade com fortes traços de um passado colonial. Ao mesmo tempo em que se apresenta como um país que se diferencia dos demais países do BRICS, paga a maior conta por continuar sendo parte dele. Pobres trabalhadores de todos os setores, cujos trabalhos, sejam materiais ou não, qualificados ou não, pagam a conta.

\section{REFERÊNCIAS}

Antunes, Ricardo. Os sentidos do trabalho. São Paulo: Boitempo Editorial, 1999.

Brasil. Ministério da Educação. Coordenação de Aperfeiçoamento de Pessoal de Nível Superior. Plano Nacional de Pós-Graduação-PNPG (2011-2020). Brasília, DF: CAPES, dez. 2010. $2 \mathrm{v}$.

CEPAL. Comissão Econômica para a América Latina e o Caribe. O Investimento Estrangeiro Direto na América Latina e Caribe. Santiago: CEPAL, 2010.

Chesnais, François. A mundialização do capital. São Paulo: Xamã Editora, 1996.

Duarte, Newton. A pós-graduação e o modelo produtivista do fazer científico. PainelBoletim Informativo da Faculdade de Ciências e Letras/UNESP, Araraquara, p. 6-7, set. 2002.

INEP. Sinopse Estatística da Educação Superior 2000. Brasília, DF: O Instituto, 2001. Disponível em: < http://portal.inep.gov.br/superior-censosuperior-sinopse>. Acesso em: 5 fev. 2012. 
. Sinopse Estatística da Educação Superior 2010. Brasília, DF: O Instituto, 2011. Disponível em: <http://portal.inep.gov.br/superior-censosuperior-sinopse>. Acesso em: 5 fev. 2012.

Investimento estrangeiro no Brasil deve bater recorde neste ano. Editorial. Folha de S. Paulo [online], São Paulo, 14 set. 2011. Não paginado. Disponível em: <http://www1. folha.uol.com.br/fsp/poder/po1409201111.htm>. Acesso em: 15 set. 2011.

Kutney, Pedro. Montadoras enviam ao exterior US $\$ 5,58$ bi faturados no Brasil em 2011. Revista UOL [online], 27 jan. 2012. Não paginado. Disponível em: <http://carros. uol.com.br/ultnot/2012/01/27/montadoras-fazem-remessa-recorde-de-us-56-bilhoesao-exterior-em-2011.jhtm>. Acesso em: 27 jan. 2012.

LukÁcs, György. Ontologia do ser social. Os princípios ontológicos fundamentais de Marx. São Paulo: Livraria Editora Ciências Humanas, 1979.

Prolegômenos para uma ontologia do ser social. São Paulo: Boitempo, 2010.

Oliveira, Francisco. Privatização do público, destituição da fala e anulação da política: o totalitarismo neoliberal. In: .; PAoli, Maria Célia. Os sentidos da democraciapolíticas do dissenso e hegemonia global. Petrópolis: Editora Vozes; FAPESP, 1999. p. $55-81$.

A face do horror. In: Silva Júnior, João dos Reis; Sguissardi, Valdemar. Novas faces da educação superior no Brasil: reformas do estado e mudanças na produção. 2. ed. rev. São Paulo: Cortez; Bragança Paulista: USF-IFAN, 2001. p. 7-13.

Paulani, Leda. A Autonomização das verdadeiras formas sociais na teoria de Marx: comentários sobre o dinheiro no capitalismo contemporâneo. In: EnCONTRO NACIONAL DE Economia, XXXVII, dez. 2009, Foz do Iguaçu. Anais... Rio de Janeiro: ANPEC, 2009.18p.

.; Oliveira, Francisco de. Financialization and barbarism: a perspective from Brazil. In: Veltemeyer, Henry; Bowles, Paul (Org.). National Perspectives on Globalization. Hampshire: Palgrave Macmillan, 2007. p. 13-27.

Sguissardi, Valdemar; Silva Júnior, João dos Reis. Trabalho intensificado nas federais: pós-graduação e produtivismo econômico. São Paulo: Xamã Editora, 2009.

Silva Júnior, João dos Reis; Sguissardi, Valdemar. Novas faces da educação superior no Brasil: reforma do Estado e mudança na produção. 2. ed. São Paulo: Cortez Editora; Bragança Paulista: EDUSF, 2001.

.; Silva, Eduardo Pinto e; Kato, Fabíola Bouth Grello; Rodrigues, Luciana; Monteiro, Rosana Batista; Martins, Tânia Barbosa. Os significados do trabalbo do professor pesquisador na universidade estatal pública mercantilizada. Relatório Científico Parcial [Processo FAPESP n. 2009/08661-0]. São Paulo: [s.n.], set. 2010.

- Os significados do trabalho do professor pesquisador na universidade estatal pública mercantilizada. Relatório Científico Final [Processo FAPESP n. 2009/08661-0]. São Paulo: [s.n.], set. 2011. 


\section{SOBRE OS AUTORES}

João dos Reis Silva Júnior é doutor em educação pela Pontifícia Universidade Católica de São Paulo (PUC-SP) e livre-docente pela Universidade de São Paulo (USP). Professor da Universidade Federal de São Carlos (UFSCAR).

E-mail: joaodosreissilvajr@gmail.com

Luciana Rodrigues Ferreira é doutoranda em educação pela Universidade Federal de São Carlos (UFSCAR).

E-mail: lucianarofer@gmail.com

Fabíola Bouth Grello Kato é doutoranda em educação pela Universidade Federal de São Carlos (UFSCAR).

E-mail: fabiola_kato@hotmail.com

Recebido em março de 2012

Aprovado em junho de 2012 
JOÃO DOS REIS SILVA JÚNIOR, LUCIANA RODRIGUES FERREIRA E FABÍOLA BOUTH GRELLO KATO

\section{Trabalho do professor pesquisador diante da expansão da pós-graduação no Brasil pós-LDB}

O texto busca contribuir para a discussão e entendimento da mudança nas universidades públicas, especialmente para a compreensão do trabalho docente na expansão da pós-graduação, nas décadas de 1990 e 2000, quando o país busca atualizar seus fundamentos econômicos ao trânsito do Regime Monopolista de Acumulação para o Regime de Acumulação Financeira e as estruturais consequências para as instituições republicanas, com enfática atenção para a universidade pública. No artigo em pauta, o interesse recai sobre a mudança do professor pesquisador em face da acentuada expansão da pós-graduação brasileira e as consequências para 
o ser social trabalhador, o significado de seu trabalho e o sentido que atribui à sua vida por esta mediação fundamental.

Palavras-chave: expansão nas universidades públicas; trabalho docente; pós-graduação.

The work of research professors in the face of the expansion of graduate education after LDB

The text seeks to contribute to the discussion and understanding of the change in public universities, especially to understand teaching in the expansion of graduate studies in the 1990s and 2000s, when the country sought to upgradeladequate its economic fundamentals to the transition from the Monopoly Accumulation Regime to the Financial Accumulation Regime and its structural consequences for the republican institutions, with a strong emphasis on the public university. This article focuses on the change of research professors in the face of the sharp expansion of graduate studies in Brazil and its consequences for them as social beings who work, the meaning of their work and the sense that they attach to their lives due to this fundamental mediation.

Keywords: expansion of public universities; teaching; graduate studies.

\section{Trabajo del profesor investigador ante la expansión del posgrado en Brasil después de la LDB}

El propósito de este articulo es contribuir a la discusión y a la comprensión de los cambios de las universidades públicas brasileñas, especialmente para conocer el alto nivel de expansión en la universidad pública en el periodo de transición desde el régimen de la acumulación de monopolio para el de la acumulación financiera en los años 1990 y 2000. Este estructural hecho histórico ha traído profundas consecuencias para las instituciones republicanas, especialmente la universidad. En el presente artículo el interés se centra en el cambio del profesor investigador ante la marcada expansión del posgrado brasileño y las consecuencias para el ser social trabajador y el significado que esa mediación fundamental atribuye a su vida.

Palabras clave: la expansión de las universidades públicas; trabajo del profesor; la expansión del posgrado. 